\title{
A QUÍMICA NAS COISAS DO COTIDIANO: INSERÇÃO DA CIÊNCIA LÚDICA PARA CRIANÇAS DA PERIFERIA DE MANAUS-AM
}

\author{
Claudenor de Souza Piedade ${ }^{56}$ \\ Aline dos Santos Pedraça ${ }^{57}$ \\ Antônio Estanislau Sanches ${ }^{58}$ \\ Cristiane Araújo dos Santos ${ }^{59}$ \\ Marcos Kleber Souza do Carmo ${ }^{60}$ \\ Shigeaki Ueki Alves da Paixão ${ }^{61}$
}

\begin{abstract}
RESUMO
A exposição de atividades que buscam motivar as pessoas a participar das atividades que agregam conhecimento pelas práticas do cotidiano, é um fator motivador frente ao desafio de desvincular o olhar dos mesmos para atividades que o fazem distrair, como os jogos, uso de celulares, tabletes e televisores que apresentam atividades que entretém e que pouco agregam na formação. A iniciativa de subsidiar meios que resgatam o valor das atividades experimentais, voltadas a instrução, pela metodologia de projetos, valorizando o saber pela percepção do meio onde vive e agregando saberes pela combinação, de brincadeiras, desafios e aplicações de novas metodologias. Construir o cenário de um laboratório que valoriza as coisas do cotidiano, como os instrumentos, os alimentos, os medicamentos, materiais de limpeza, de higiene e outros, fazendo com que a percepção da ciência seja importante para a construção de uma pratica de vida sustentável. A utilização de forma lúdica de insumos do dia a dia social é uma forma de resgatar a motivação das pessoas para se integrar em grupos de trabalho, oficinas de construção do conhecimento e busca de identidade, destacando o valor do uso de tecnologias, ações elaboradas inovadoras e capacitação pelo viés diferenciado para levar a mensagem de integração. O papel do cidadão é valorizar a ciência pelas suas práticas e poder de transformação, mas a atração deve motivar a participação, integrando a todos às experiências, conduzindo a comunidade para a inclusão dentro de uma proposta norteadora e voltada a melhorar o rendimento dos estudantes, valorização das boas práticas do cotidiano e a capacitação de todos. Neste estudo o destaque está para a valorização do saber empírico e a motivação pela apresentação de um fator interessante que se explica pelas ações corriqueiras. O processo é de forma itinerante, aplicado em comunidades que tem déficit de aprendizagem, alta desistência escolar e problemas de conflitos familiares e uso de álcool e drogas. As atividades são realizadas com a explanação, participativa de experimentações com coisas da comunidade e a explicação de suas propriedades.
\end{abstract}

Palavras-chave: Lúdico, Química das coisas; conhecimento; saberes.

\footnotetext{
${ }^{56}$ Mestre em Biotecnologia Pela Universidade do Estado do Amazonas-UEA; Professor pela Secretaria do Estado da Educação do Amazonas-SEDUC-AM; Membro do Grupo de Pesquisa do CNPQ: A Geomática na Construção Civil, nos Transportes e no Meio Ambiente; Aliança em inovações tecnológicas e ações sociais AITAS-AM - $2^{\circ}$ secretário. E-mail: claubertcaetano@gmail.com

${ }^{57}$ Mestranda em Engenharia Elétrica -PPGEE/UFAM, 2021; Mestra em Serviço Social e Sustentabilidade na Amazônia-PPGSS IUFAM; Engenheira Eletricista -UNINORTE-AM. Bacharela em Serviço Social -UNINILTON LINS - AM; Membro do Grupo de Pesquisa do CNPQ: A Geomática na Construção Civil, nos Transportes e no Meio Ambiente; Aliança em inovações tecnológicas e ações sociais AITAS-AM -Vice-Presidente. E-mail: Alinepedraca7@gmail.com.

${ }^{58}$ Universidade Nilton Lins (UniNilton Lins) -Amazonas -Brasil. Membro do Grupo de Pesquisa do CNPQ: A Geomática na Construção Civil, nos Transportes e no Meio Ambiente; Aliança em inovações tecnológicas e ações sociais AITAS-AM, Associado, Brasil- Manaus-Amazonas. E-mail: novo.sanches@gmail.com.

${ }^{59}$ Centro Universitário do Norte - UNINORTE- Engenheira Eletricista;

${ }^{60}$ UNINILTON LINS - Engenheiro Civil - Manaus- Amazonas, Brasil. Aliança em inovações tecnológicas e ações sociais AITAS-AM, Associado, Brasil- Manaus-Amazonas. E-mail:

${ }^{61}$ Doutorando do Programa de Pós-Graduação Sociedade e Cultura na Amazônia -PPGSCA -IFCHS -UFAM. Email: shigeakiturismo@hotmail.com
} 


\title{
CHEMISTRY IN EVERYDAY THINGS: INSERTION OF LUDIC SCIENCE FOR CHILDREN FROM THE OUTSIDE OF MANAUS-AM
}

\begin{abstract}
The exhibition of activities that seek to motivate people to participate in activities that add knowledge through everyday practices, is a motivating factor in the face of the challenge of detaching their eyes from activities that make them distracting, such as games, use of cell phones, tablets and televisions that present activities that entertain and that add little to training. The initiative to subsidize means that rescue the value of experimental activities, focused on instruction, through the methodology of projects, valuing knowledge through the perception of the environment where it lives and adding knowledge through the combination, of games, challenges and applications of new methodologies. Build the scenario of a laboratory that values everyday things, such as instruments, food, medicines, cleaning materials, hygiene and others, making the perception of science important for the construction of a sustainable life practice. The playful use of everyday social inputs is a way to rescue people's motivation to integrate into work groups, knowledge-building workshops and the search for identity, highlighting the value of using technologies, innovative elaborated actions and training through a different approach to carry the message of integration. The citizen's role is to value science for its practices and transformative power, but the attraction must motivate participation, integrating everyone into the experiences, leading the community towards inclusion within a guiding proposal and aimed at improving student performance, valuing good daily practices and training for all. In this study, the highlight is the valorization of empirical knowledge and the motivation for presenting an interesting factor that can be explained by common actions. The process is itinerant, applied in communities that have a learning deficit, high school dropout and problems with family conflicts and alcohol and drug use. The activities are carried out with the explanation, participatory of experiments with things of the community and the explanation of their properties.
\end{abstract}

Keywords: Playful, Chemistry of things; knowledge; knowledges

\section{INTRODUÇÃO}

Pode até parecer insignificante, mas é nos primeiros momentos da vida que são firmadas as informações que hão de nortear a trajetória dos indivíduos, a construção dos gestos e de todo o arcabouço que vai permitir sua capacidade de tomar decisões, de construir para si um universo de padrões que ditarão o seu ser.

Cavadas (2021) descreve que na fase de desenvolvimento dos indivíduos e na sua trajetória instrucional ele absorve informações que subsidiam capacidades, a educação como premissa de escolhas deve ser fundamentada em conceitos sólidos que ditam valores e senso de justiça, para que a intransigência não transgrida a níveis exorbitantes.

A realidade das sociedades é que o advento das tecnologias e a inclusão a universos mais automatizados é chamativo e discriminatório, onde alguns poucos absorvem, interagem e solucionam problemas, mas outros se tornam "meros" de um sistema de exclusão. Estar no meio não significa que está incluso. 
Manipular teclas em um celular, computador ou outro instrumento não significa que tem capacidades privilegiadas, acaba por endossar uma lista de pessoas que estão aptas a marginalização e isso não é pro escolhas ou opção é por ignorância mesmo. Pois se é desconhecido e está ao alcance a experimentação pode ser de impacto absurdo e desestruturante.

A que caminhos a sociedade brasileira, em expectativa, as comunidades de zonas periféricas da Cidade de Manaus. Como caminha o processo de formação e inclusão a conceitos de valores e atitudes baseados em ciência, de fato? Dados destaca quem antes da crise sanitária ocasionada pela COVID 19 que assolou o planeta, o estado do Amazonas já investigava os desvios de recursos públicos, corrupção, tráfico de influência e outras formas de corrupção que passam a efetivar práticas de crimes contra o bem público como normais, onde a situação da distribuição de emprego e renda cada vez mais empurra os menos abastados para a informalidade e cria um cenário de construção do crime e desconstrução social pela educação formalizada.

Com o aumento da pobreza, aumenta os problemas sociais, pois as pessoas vão em busca de sobrevivência aí o crime se torna a porta aberta. Muitas crianças de periferia nem sequer são mapeadas para as práticas educacionais, até sonham em ser alguém na vida, mas na falta de oportunidades se tornam alvo preferencial para o trafico de drogas, para a exploração e o desencadear de um mundo sem perspectivas.

Com a perspectiva de que as comunidades têm dificuldades de acesso a informação e muitas das vezes a motivação vêm das atividades ilícitas é que a Aliança em inovações tecnológicas e Ações Sociais no estado do Amazonas (AITAS-AM) implementou o projeto Química das coisas do cotidiano, trata-se de uma atividade voltada a levar ciência, um olhar voltado para a química, a crianças das periferias das comunidades da zona metropolitana de Manaus.

$\mathrm{Na}$ execução do projeto são apresentadas ações que mostram o valor das coisas, mas o valor na sua forma instrutiva, agregando aos aspectos lúdicos para atrair a atenção e motivar a tomada de decisão a favor da ciência. Se trata de uma atividade que se justifica pelo despertar pela exibição de cores, explosão e movimento, trazendo o lúdico para ser explicado com serenidade e simplicidade.

Dentro das ações as atividades são organizadas em seção própria para exibição dos produtos e as experiencias são aplicadas com a interação da comunidade, pois mesmo sendo uma atividade voltada para crianças, os adultos também participam e interagem, isso mostra a relevância das atividades e pontua a falta de acesso à ciência de forma efetiva e construtiva. 
O despertar das intenções em visualizar o valor do conhecimento nas coisas que são aplicadas no cotidiano credenciam o projeto como uma maneira de resgate, de favorecer o reencontro que deveria ser facilitado pelos sistemas educacionais, uma aproximação da ciência experimental como fundamento de busca do conhecimento, permitindo que mais crianças, jovens e adultos possam conhecer e se blindar das ações escusas que a sociedade cultua pela ignorância.

\section{DESENVOLVIMENTO}

\section{1- A Aliança em Inovações Tecnológicas e Ações Sociais no Estado do Amazonas- AITAS-AM}

Fundada aos onze dias do mês de fevereiro de dois mil e vinte (11.02.2020) a AITASAM é uma entidade de Classe, com sede e atuação na Cidade de Manaus-AM, da Sociedade Civil, sem fins lucrativos, tendo por finalidade, integrar pessoas seja no contexto social quanto profissional, tem o compromisso social em acionar soluções de forma integradas para promover desenvolvimento social, empresarial e profissional.

Dentro de uma expectativa de crescimento e responsabilidade social, busca excelência em serviços, pois a valorização das pessoas é o foco principal para que haja integração e respeito aos profissionais da Engenharia, tecnologias e áreas afins.

Trata-se de uma entidade voltada a levar o profissional nos locais de impacto, através de ações sociais, realização de projetos, educacionais, ambientais e de infraestrutura. A assistência a pessoas em vulnerabilidade social surge da necessidade de pessoas que participam das ações, da vivência da equipe da AITAS-AM em projetos de inclusão social.

A AITAS-AM não faz assistencialismo, tende a promover a integração de pessoas ao universo da ciência, pois é dotada de profissionais de vários segmentos (equipe multiprofissional), no setor de trabalho, com cursos de formação profissional, inserção de estágio e acompanhamento de pessoas com dificuldades e vulnerabilizadas.

Prioriza as pessoas, que junta soluções de inovações tecnológicas para a implementação nas comunidades, entidades e setores da sociedade onde falta infraestrutura. O setor de serviços voltado a atender o profissional nas mais diferentes instâncias de atuação, recai para o terceiro setor. Com um grupo de Profissionais multitarefas, com a engenharia e profissionais das áreas tecnológicas em foco. 
O grupo de profissionais tem formação diversificada e atende a vários aspectos de demanda. A relação da AITAS com os órgãos governamentais, entidades privadas, empresas e empresários é bastante solicitada e formal. No campo dos projetos planeja, executa e formaliza estruturas que contemplam as inovações tecnológicas, reciclagem, implementação de saúde preventiva, criatividade, intervenção em ambientes deteriorados, casas insalubres, políticas de intervenção para ajuste de ação com apoio das comunidades, de associações e outros.

\subsection{O setor Educacional e as interrelações}

A escola nos moldes tradicionais acaba por postergar o acesso da ciência que explica as coisas do cotidiano, para uma apresentação tardia e causa um impacto na formação do estudante. Tal distanciamento ocasiona na falta de interesse dos estudantes pela escola, pelo aprendizado significativo e pela ciência em si, e agem como se a escola seja uma obrigação, uma espécie de "castigo" sem um significado lógico, isso reflete nos resultados de proficiência e na escolha e desempenho nas profissões.

Nogueira (2018) mostra que inúmeros são os fatores de desinteresse dos estudantes, o que perpassa pela ausência de motivação e isso monta de muitos motivos que descontroem a capacidade de sentir prazer em apreciar o desenvolvimento de um evento, se o desconhece.

Atualmente, a educação compete com inúmeros meios de entretenimento, uma realidade que é forjada pela atitude de muitos pais, que para manter seus filhos ocupados, disponibilizam celulares, tablets, videogames e outros, alienando-os a um olhar vazio no exercício do pensamento. A inserção de tais mecanismos de distração fazem dessas práticas um fator de resistência para as boas práticas metodológicas, e que muitas das vezes o efeito não surte o efeito como esperado.

Pereira (2017) destaca que a tecnologia e os meios de difusão da informação têm que favorecer o crescimento do intelecto e da capacidade de raciocínio, por isso deve ter o acompanhamento e um fim, não um entretenimento para se livrar do problema "os filhos".

A dimensão curricular da escola atual e os objetivos que se buscam com a inserção de dinâmica de projetos integradores, abre a possiblidade de novas práticas de inclusão e, aciona situações que tendem a expandir o alcance das ciências capaz de motivar a integração dos alunos nas práticas escolares.

Segundo Aguiar (2018) a Base Nacional Comum Curricular vem na contramão das aplicações da educação no cenário atual, por ela vem outras perspectivas de acionar os projetos 
e redimensionar os problemas, uma vez que os resultados em nível educacional têm certos gargalos a serem redefinidos.

Não se deve desconsiderar que a aplicação de tecnologias nas escolas e uso de ferramentas de da informação, sem o devido acompanhamento e direcionamento pedagógico planejado, sejam propensos ao fracasso, pois a ação mecânica na atuação da execução, inibe o que se espera dos alunos, o exercício do pensamento, mas com uma dosagem de incentivo esse quadro pode, paulatinamente, se reverter, onde a escola seja, com suas atividades um elo atrativo entre o ambiente familiar e o espaço escolar.

A ideia aqui mencionada traz a perspectiva de acionar as ferramentas que se manifestam no lúdico, o despertar da criança que existe na infância e que à medida que se vai amadurecendo, essa condição vai ficando para segundo plano.

A sociedade tende a doutrinar as ações de seus indivíduos para agir de acordo com as normas e tendências, frisando as responsabilidades e condições de sobrevivência. Mas, quando esse indivíduo não foi apresentado ao universo das escolhas maduras e embasadas, se torna alvo fácil para a promiscuidade e a porta para as drogas, prostituição, delinquência e outros são as únicas opções de agregar valores a um vazio existencial que existe em suas vidas.

\subsection{O que fundamenta a realização de experiencias de ciências nas comunidades periféricas?}

As atividades, que são realizadas nas comunidades da zona metropolitana de Manaus, através de um grupo de trabalho na Aliança em Inovações tecnológicas e Ações Sociais no Estado do Amazonas (AITAS-AM), onde se leva as experiências da química básica, dentro das ações sociais para explicar as propriedades dos produtos de limpeza, alimentos, medicamentos, vestuários, higiene, meio ambiente e outros.

São atividades subsidiadas por uma equipe que detém profissionais que se voluntariam para a participação em ações a favor da humanização das ações, se define em execução de projetos de aulas lúdicas com matérias da química aplicada nas coisas do cotidiano.

Martins (2017) cita que a ciência aplicada em ambiente aberto e voltada para validar certos fatores, que por horas invisíveis para a população, acende e resgata uma divida que o sistema de educação tem com a sociedade. $\mathrm{O}$ ensino tem que ser instrutivo ao passo de permitir escolhas maduras e pautadas no conhecimento. 
A responsabilidade de quem visualiza as comunidades e percebe um distanciamento entre a realidade e o que é possível intervir nas conformidades que dão vida ao crime e a usurpação de saberes e ideias. A ciência tem que fazer despertar a curiosidade das pessoas, onde se busque elucidar as ocorrências dos fenômenos e sua necessidade para instruir sobre a vida, preceitos de alimentação, bem estar e adaptabilidade. Como se considera a celebre frase de Lavoisier" Na natureza nada se perde, nada se cria, tudo se transforma" (LEITE, 2020, p. 173).

De acordo com Pereira (2017) a amplitude de fazer o "tecer junto" com a preconização de Edgar Morin, permite acionar meios que possibilitam a realização de ações capazes de motivar pelo fazer e fazer juntos.

A integração da AITAS nas comunidades valida o olhar multifuncional de profissionais de vários seguimentos que convergem entre si, para levar a mensagem da autoconfiança, primeiro pela presença nos locais, acende a chama do querer seguir, a humanização das ações responde à questão do valor de quem valoriza as pessoas com suas habilidades e deficiências, assim como a oportunidade de vivenciar uma realidade que faz parte de seu cotidiano, mas que não visualiza os fundamentos.

\section{METODOLOGIA}

O método realizado exibe as experiências integrando as crianças em suas realizações e no desenvolvimento a explicação das propriedades, os valores do conhecimento, o que se tem de conhecido e o desvendamento de mitos e propostas enganosas. As atividades são realizadas nas escolas, nos núcleos comunitários, onde a equipe do projeto nas ações sociais da AITASAM. A estratégia do projeto é aproveitar tudo do cotidiano das pessoas, como: instrumentos, alimentos, medicamentos, alimentos e contrastar com os materiais de laboratório, os reagentes químicos e a sua classificação.

As experiências são feitas com foco na percepção das crianças, que muitas das vezes, se sentem desmotivadas por não perceberem muita motivação na escola pelas cobranças, muitas das vezes, falta de inovações. As atividades colaboram com os profissionais da educação, de modo itinerante, para motivar o ensino da ciência nas escolas, fazendo inserir a química de forma lúdica e responsável, levando informações que vão colaborar com o conhecimento das crianças e motivar a interação em atividades escolares.

A equipe do projeto selecionar as atividades por demandas, fazendo um levantamento das zonas da cidade de Manaus onde exista a maior problemática de baixo rendimento e evasão 
escolar, primeiramente, aplicar as atividades para crianças e a comunidade escolar, como pais, colegas, e demais pessoas das comunidades. São selecionadas as comunidades que se identifica problemas de aprendizagem, alto índice de problemas de pobreza e marginalidade.

Como contrapartida, as atividades em algum momento são aplicadas em escolas com a participação dos professores que aderirem às práticas lúdicas de projetos como fator de motivação das crianças pela explanação das informações motivadoras pelas práticas do dia a dia.

\section{RESULTADOS E DISCUSSÃO}

O projeto Química nas coisas do cotidiano surgiu quase que, concomitantemente, com a AITAS-AM, ele é pensado como um chamamento para atrair as pessoas para o ambiente das ações, à medida que as experiências são aplicadas as pessoas sentem o impacto nas suas vidas e relatam suas experiencias e frustrações pela ausência de informação.

Engler (2018) destaca que a errância do filósofo platônico acerca do dogmatismo, ignorância e aporia, uma vez que nenhum homem mau ou ignorante ama a sabedoria (philosphein) pois aqueles que tem em si o mal, a ignorância, sem que por causa disso se tornem ignorantes e insensatos, senão que reconheçam que não sabem acerca das coisas que ignoram.

A cultura da desconstrução do saber é conveniente para enganar e alienar, as culturas e as formas de vida de certas civilizações são marcadas por interferências externas que causam colapsos e, muitas das vezes tendem a arruinar sua existência e quando não se faz destruir na essência a deturpa e transforma em nada a essência.

As comunidades sofrem pela falta de instrução de aproveitamento do saber empírico que vai se destituindo com a ausência de políticas públicas, suficientemente, voltadas a inclusão de pessoas com o apropriamento do saber consolidado, mas o gotejamento de saberes, fragmentado, serve a interesse de poucos, destruindo a muitos, indiscriminadamente.

O projeto Química das coisas do cotidiano traça experiencias e relata a amplitude que seria se a educação valorizasse mais a proximidade das coisas dispostas no dia a dia da população.

A figura 1 destaca a realização de experiências para as comunidades, em ambientes improvisados, mas com foco, mas seguindo todos os parâmetros de segurança. As crianças participam das atividades com muito entusiasmo e os resultados são muito animadores, pois se percebe que a essência está ativa na estampada na face das pessoas e se percebe que a iniciativa 
é permitir que as pessoas sintam o fundamento das atividades que é incluir, participar e se posicionar.

Gimenez (2018) destaca que o conhecimento, a escola e as comunidades cumulam experiências e desvendam talentos, o mosaico de experiências que podem ser abstraídos das comunidades que sofrem sobre influência da falta de informação, que se tornam meios de agregar novos saberes e o encontro está na aceitação do aproveitamento das possibilidades.

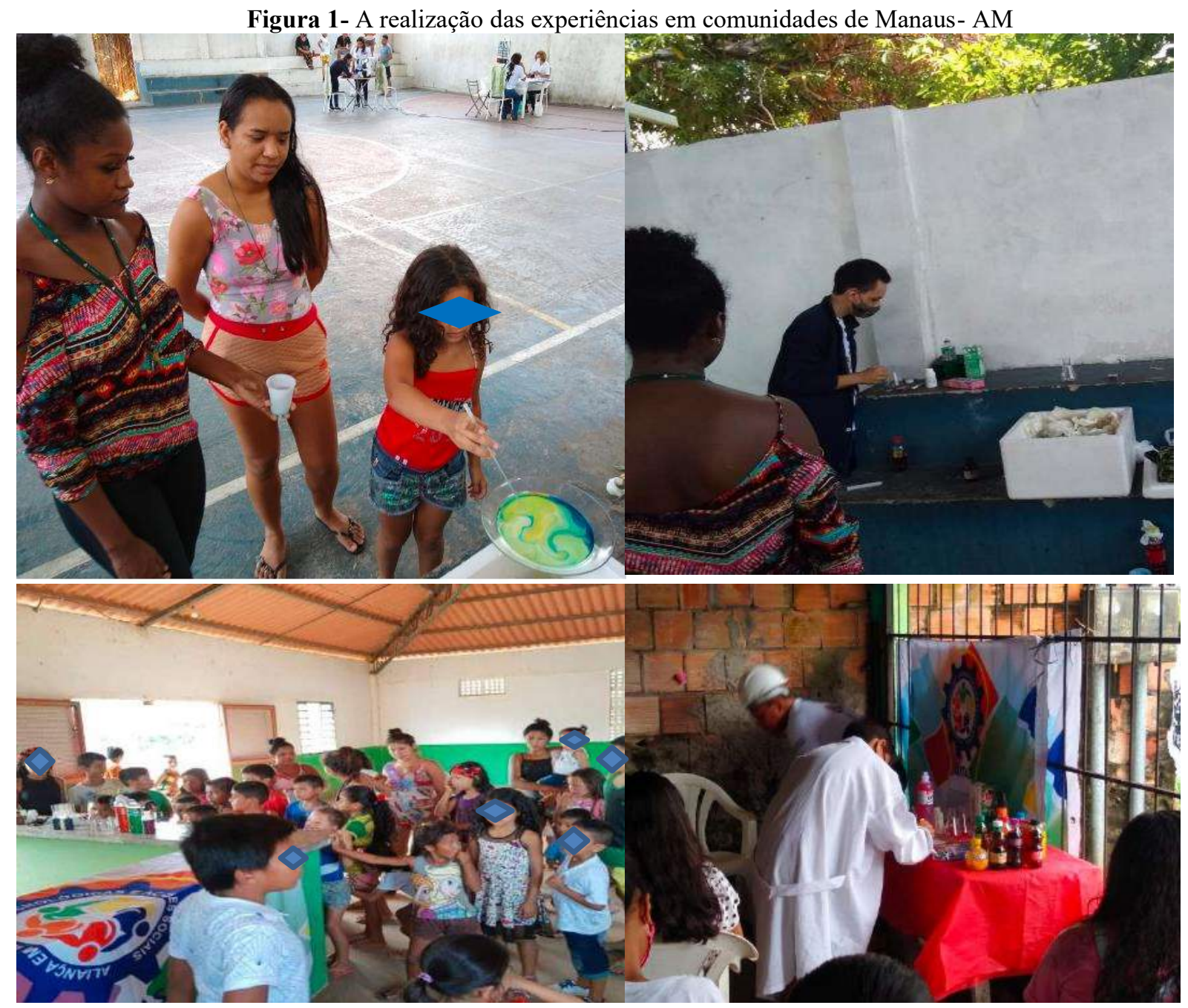

Fonte: próprio (2021)

A partilha do saber pela participação em regiões onde a escola é precarizada e as ações sociais são opção de motivação e entretenimento para as pessoas das comunidades e como se pode ver a expressão dos comunitários. Na figura 1 tem situações de realização nas zonas periféricas da cidade de Manaus e na região rural de Iranduba.

Ribeiro (2019) destaca que a formação inicial e a iniciação à docência em Química exigem que realizando as experiências e vivenciando histórias destaca a validação das 
potencialidades que podem mobilizar a utilização da química como instrumento de transformação do saber pela capacidade de integração da ciência e a comunidade.

A partilha em escolas também é uma alternativa de agregar, por isso algumas ações são realizadas em escolas que também exibem boas aplicações. A Figura 2 demonstra uma situação de uma ação em escola de Manaus e comunidades.

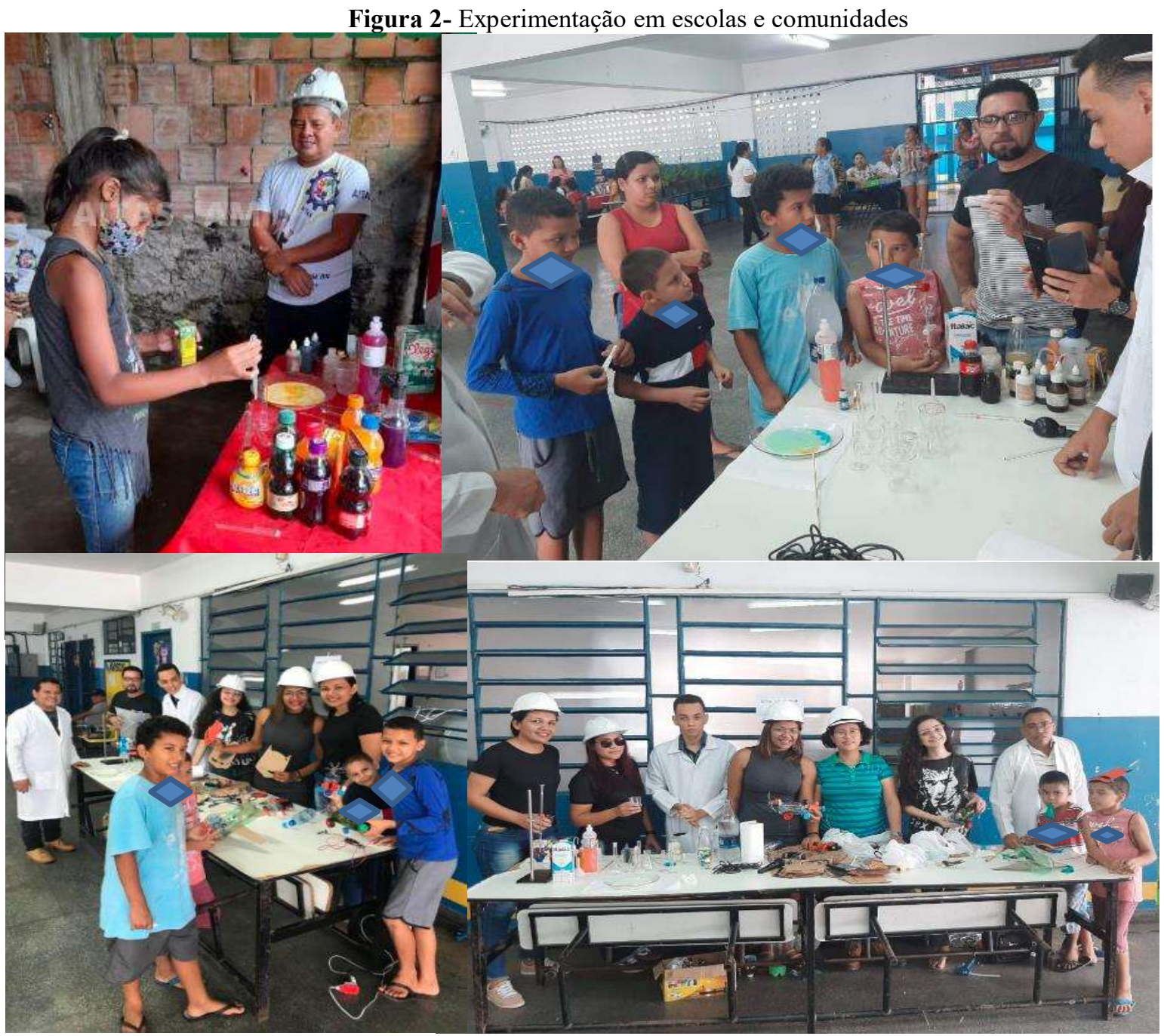

Fonte: Próprio (2021)

O projeto Química das coisas do cotidiano agrega as capacidades de explicação das propriedades dos materiais do dia a dia, a contrapartida está na forma de avaliar as boas práticas de laboratório integrando as condições pirotécnicas e de mobilidade que a ciência pode proporcionar.

Plácido (2018) destaca que o aproveitamento das propriedades dos materiais para explicar o efeito das coisas na vida das pessoas, a química é uma disciplina que favorece a expressão pela revelação de suas reações, de seus aspectos espectrais e outros. 
É denotado que nas comunidades a informação causa um impacto de reflexão para aqueles que já detém algum conhecimento e abre um leque de possibilidades para aqueles que ainda não tiveram a oportunidade de vivenciar os efeitos da ciência pelas propriedades dos materiais do uso cotidiano.

\section{CONCLUSÃO}

Valorizar o conhecimento pelo encontro com as coisas que fazem parte da vida dos estudantes, validar os saberes pela oportunidade. O lúdico deve ser alimentado, seja qual for a idade de quem utiliza a informação e executa alguma atividade.

Para que o lúdico faça presença na vida de jovens e adultos, ele deve ser efetivado na fase infantil, destacado como instrumento de aprendizagem. Esse projeto é uma forma de despertar o interesse pela ciência em crianças que estão muitos focadas nas mídias sociais, "meros telhadores de botões" e que precisam expandir seus horizontes e atuar para um aprendizado mais significativo e inclusivo.

A estruturação através da AITAS-AM para a implementação de novas formas em levar ciência para as comunidades, facilita que se destaque o olhar integrador das percepções do ambiente onde se faz as práticas do cotidiano. A educação pelos moldes tradicionais tem certas deficiências que, mesmo em escolas de alto padrão, sofre pela inoperância dos sistemas de Curricularização que depende de inúmeros fatores e sendo o mais importante, o aluno, deve aderir às práticas inovadoras.

Muitos são os esforços que se tem feito para sobrepor as dificuldades para que a escola tenha bons resultados, como por exemplo a BNCC que implementa a dinâmica de projetos na escola inovadora. Ainda assim, as ações da AITAS-AM têm mostrado que tem viabilidade a integração dos saberes com a capacitação das pessoas no intuito de adequar as capacidades, aproveitando todas as possibilidades de aprendizado e partilha.

Como sugestão de futuros trabalhos, deve ser acionado uma análise de impacto nas comunidades com a aplicação das experiências com a forma de conciliar os resultados para emancipar as comunidades e validar as atividades a favor do cidadão. 


\section{REFERENCIAS BIBLIOGRÁFICAS}

AGUIAR, Márcia Angela da S.; DOURADO, Luiz Fernandes. A BNCC na contramão do PNE 2014-2024: avaliação e perspectivas.Recife: ANPAE, p. 28-33, 2018.

CAVADAS, BENTO; SÁ-PINTO, XANA. Conceções de Estudantes portugueses em Formação Inicial de Professores Sobre a Evolução e a Origem da Vida. Revista Brasileira De Pesquisa Em Educação Em Ciências, V. 20, N. U, P. 1339-1362, 2021.

ENGLER, Maicon R. A errância do filósofo platônico: dogmatismo, ignorância e aporia. Guairacá-Revista de Filosofia, v. 34, n. 2, p. 85-109, 2018.

Gimenez, T., El Kadri, M. S., Gamero, R., \& dos Anjos-Santos, L. M. Conhecimento, escola e comunidade: experiências no âmbito do programa novos talentos. SciELO-EDUEL. 2018.

LEITE, Isabel Pereira. Verdade. Pensar, ensinar e fazer justiça: estudos em homenagem a Paulo Ferreira da Cunha, 2020.

MARTINS, Moisés de Lemos. Comunicação da ciência, acesso aberto do conhecimento e repositórios digitais. O futuro das comunidades lusófonas e ibero-americanas de Ciências Sociais e Humanas. 2017.

Nogueira, B. M., BÓ, A., Estivalet, A., \& COSTA, D. Fatores de Desinteresse e a Experimentação no Ensino de Ciências da Natureza. $X V$ Encontro sobre Investigação na Escola, Porto Alegre. 2018.

PEREIRA, Dimitri Wuo. O pensamento complexo de Edgar Morin: subsídios teóricos para a superação da fragmentada formação do professor de educação física. 2017.

PEREIRA, Flávia Maria. Impactos da Utilização das Tecnologias no Processo de Aprendizagem das crianças.ID on line REVISTA DE PSICOLOGIA, v. 11, n. 38, p. 520$529,2017$.

PLACIDO, Reginaldo Leandro; DE LUCA, Anelise Grünfeld; SOUZA, Gabriela Cristina. Uma proposta didática para o ensino de química: a aplicação do jogo químicasa. Formação@ Docente, v. 10, n. 3, 2018.

RIBEIRO, Marcel Thiago Damasceno. A Formação inicial e iniciação à Docência em Química na UFMT: histórias e experiências. Revista Prática Docente, v. 4, n. 1, p. 275-301, 2019. 